\title{
ТЕПЛОФИЗИЧЕСКИЕ ПРОЦЕССЫ ФОРМИРОВАНИЯ ЗАГОТОВОК ПРИ ВИБРАЦИОННОЙ И ГАЗОИМПУЛЬСНОЙ ОБРАБОТКЕ ЗАТВЕРДЕВАЮЩЕГО В КРИСТАЛЛИЗАТОРЕ МНЛЗ МЕТАЛЛА
}

\author{
А.С. Нурадинов, Н.С. Уздиева, С.С.-С. Ахтаев
}

Грозненский государственный нефтяной технический университет им. академика М.Д. Миллионщикова, г. Грозный, Россия

Для оптимизации работы кристаллизатора МНЛЗ изучены закономерности теплообмена между кристаллизатором и заготовкой. Показано, что вибрационное воздействие и газоимпульсное перемешивание затвердевающего металла в кристаллизаторе МНЛЗ оказывает положительное влияние на тепло- и массобменные процессы в кристаллизаторе и позволяет получать заготовки с мелкозернистой равномерно распределенной по сечению структурой.

Ключевые слова: кристаллизатор, заготовка, теплоотвод, тепловой баланс, газоимпульсное перемешивание, зона вторичного охлаждения.

Теплофизические условия формирования непрерывнолитой заготовки в кристаллизаторе МНЛЗ, а именно интенсивность охлаждения металла в кристаллизаторе и зоне вторичного охлаждения, имеет огромное значение для развития дефектов непрерывного литья. Применяя методы внешних физических воздействий в этих зонах, можно влиять на теплообменные процессы при формировании заготовок. Кристаллизатор является основным и важным узлом МНЛЗ, так как в нем за счет теплоотвода от жидкого металла формируется первичная оболочка непрерывнолитой заготовки. Для того, чтобы выдерживать ферростатический напор жидкой фазы и силы трения между оболочкой и стенками кристаллизатора, затвердевшая оболочка заготовки должна иметь достаточную толщину. Для оптимизации конструкции кристаллизатора и 
режимов теплоотвода необходимо знать закономерности теплообмена между заготовкой и кристаллизатором.

Теплота, отводимая от заготовки в кристаллизаторе, состоит из [1]:

$$
Q_{\kappa p}=Q_{n е p}+Q_{\kappa o p}
$$

где $Q_{\text {пер }}$ - тепло перегрева стали над $t_{л}$, поступающей в кристаллизатор; $Q_{\kappa o p}$ - тепло, которое необходимо отвести для формирования корки.

Тепло перегрева стали определится из равенства [1]:

$$
Q_{n e p}=m_{\kappa p} C_{\varkappa}\left(t_{n \kappa}-t_{л}\right)
$$

где $m_{\kappa p}$ - масса столба металла в кристаллизаторе от мениска до нижнего среза кристаллизатора; $C_{ж}$ - теплоемкость жидкой стали; $\quad t_{n \kappa}-$ температура металла в промежуточном ковше; $t_{n}$ - температура ликвидус.

Интересующая нас компонента $Q_{\kappa p}$ определяется из выражения [1]:

$$
Q_{\kappa p}=G_{6} c_{6} \Delta t_{b} \tau
$$

где $G_{6}$ - расход воды на охлаждение кристаллизатора; $C_{6}-$ удельная теплоемкость воды; $\Delta t_{b}-$ перепад температуры охлаждающей воды на выходе и входе в кристаллизатор; $\tau$ время пребывания металла в кристаллизаторе.

Массу затвердевающего металла в кристаллизаторе:

$$
m_{\kappa p}=S h_{a} \rho,
$$

где $S$ - площадь поперечного сечения полости кристаллизатора; $h_{a}$ - активная высота кристаллизатора (расстояние от мениска металла до нижнего среза); $\rho$ - удельный вес пребывающего в кристаллизаторе металла. 
Теплота, которую нужно отвести для формирования корки [5]:

$$
Q_{\kappa o p}=m_{3}\left[\left(q+C_{\text {э }}\left(t_{n \kappa}-t_{n}\right)+C_{m}\left(t_{l}-t_{o \sigma}\right)\right]\right.
$$

где $m_{3}$ - масса затвердевшей корковой оболочки; $q$ - удельная скрытая теплота кристаллизации; $C_{m}-$ теплоемкость затвердевшей стали; $t_{\text {об }}$ - средняя температура затвердевшей корки.

С учетом изложенного выше, для рассматриваемой массы металла $m_{\kappa p}$ в кристаллизаторе уравнение теплового баланса (1) принимает вид:

$$
m_{3}\left[q+C_{\mathcal{F}}\left(t_{n \kappa}-t_{l}\right)+C_{n c}\left(t_{l}-t_{\circ \sigma}\right)\right]+n Q_{n e p}=Q_{\kappa p}=Q_{6} C_{6} \Delta t_{6} \tau,(6)
$$

где $n$ - доля тепла перегрева 0,25 .

Массу затвердевшей корки слитка определяют из уравнения (6):

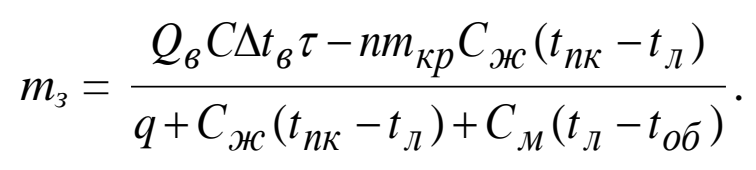

Зная количество отводимого в кристаллизаторе тепла, можно определить среднее значение коэффициента теплоотдачи $\alpha_{c p}$ от расплава к его стенкам:

$$
\alpha_{c p}=Q_{k p} / F_{k p} \Delta t_{k p},
$$

где $\alpha_{c p}$ - коэффициент теплоотдачи в кристаллизаторе, кДж/м ${ }^{2} \mathrm{C}$; $Q_{\kappa p}$ - тепло, отведенное в кристаллизаторе, кДж; $F_{\kappa p}-$ площадь поверхности стенок кристаллизатора, $\mathrm{m}^{2} ; \Delta t_{\kappa p}-$ перепад температуры между расплавом и стенками кристаллизатора, ${ }^{\circ} \mathrm{C}$.

По зависимостям (1-8) можно провести анализ теплового баланса кристаллизатора и определить массу и толщину затвердевшей корочки металла. 
Таблица 1 - Влияние вибрации на формирование блюмовой заготовки

\begin{tabular}{|c|c|c|c|c|c|c|c|c|c|}
\hline \multirow{4}{*}{$\begin{array}{c}\text { Наименование } \\
\text { параметра }\end{array}$} & \multirow{4}{*}{ 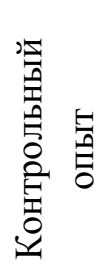 } & \multicolumn{8}{|c|}{ Опыты с вибрацией } \\
\hline & & \multirow{2}{*}{\multicolumn{4}{|c|}{$\begin{array}{c}\text { амплитуда } A=0,2 \text { мм } \\
\text { частота } v, \Gamma ц\end{array}$}} & \multirow{2}{*}{\multicolumn{4}{|c|}{$\begin{array}{c}\text { амплитуда } A=0,5 \text { мм } \\
\text { частота } v, \text { Гц }\end{array}$}} \\
\hline & & & & & & & & & \\
\hline & & 19 & 31 & 47 & 61 & 19 & 31 & 47 & 61 \\
\hline $\begin{array}{l}\text { Тепло, отведенное в } \\
\text { кристаллизаторе, кДж }\end{array}$ & 3681 & 4190 & 4402 & 4547 & 4630 & 4390 & 4710 & 4820 & 5000 \\
\hline $\begin{array}{l}\text { Коэффициент } \\
\text { теплоотдачи, кДж/м² } \\
{ }^{\circ} \mathrm{C}\end{array}$ & 4601 & 7501 & 8695 & 9998 & 10380 & 9785 & 11520 & 13032 & 13660 \\
\hline $\begin{array}{l}\text { Толщина корки на } \\
\text { выходе из } \\
\text { кристаллизатора, мм }\end{array}$ & 13 & 12 & 11 & 10 & 10 & 11 & 10 & 9 & 9 \\
\hline $\begin{array}{l}\text { Средняя скорость } \\
\text { кристаллизации, } \\
\text { мм/мин. }\end{array}$ & 1,6 & 1,8 & 2,0 & 2,1 & 2,2 & 2,0 & 2,2 & 2,5 & 2,8 \\
\hline $\begin{array}{l}\text { Масса затвердевшего } \\
\text { сплава, кг }\end{array}$ & 0,22 & 0,27 & 0,42 & 0,54 & 0,79 & 0,47 & 0,79 & 1,08 & 1,35 \\
\hline $\begin{array}{l}\text { Глубина жидкой } \\
\text { лунки, м }\end{array}$ & 1,2 & 1,0 & 0,85 & 0,75 & 0,6 & 0,8 & 0,6 & 0,45 & 0,35 \\
\hline
\end{tabular}

Сравнительные результаты расчета параметров (по зависимостям 1-8) теплового баланса и некоторые другие параметры формирования блюмовой непрерывнолитой заготовки под воздействием вибрации и газоимпульсного перемешивания приведены в таблицах 1 и 2.

Из анализа даннях таблицы 1 видно, что максимальный темп роста тепловых параметров формирования заготовок наблюдается при увеличении частоты вибрации с 0 до 47 Гц независимо от амплитуды. Коэффициенты теплоотдачи от расплава к стенкам кристаллизатора в этих пределах возрастают до 2,3 раз при $A=0,2$ мм и до 3,0 раз при $A=0,5$ мм.

Теплота, отводимая в кристаллизаторе, в этом случае возрастает, соответственно, на: $26 \%$ при $A=0,2$ мм и на $36 \%$ при $A=0,5$ мм. 
Таблица 2 - Влияние газоимпульсного перемешивания расплава на формирование блюмовой заготовки

\begin{tabular}{|c|c|c|c|c|c|c|c|}
\hline \multirow{4}{*}{$\begin{array}{c}\text { Наименование } \\
\text { параметра }\end{array}$} & \multirow{4}{*}{ 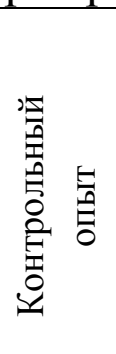 } & \multicolumn{6}{|c|}{ Опыт с газоимпульсным перемешиванием } \\
\hline & & \multirow{2}{*}{\multicolumn{3}{|c|}{$\begin{array}{c}\text { глубина погружения } \\
\text { стакана (СБО) } \\
h=55 \text { мм } \\
\text { частота } v, \text { Гц }\end{array}$}} & \multicolumn{3}{|c|}{$\begin{array}{c}\text { глубина погружения } \\
\text { стакана (СБО) } h=75 \text { мм }\end{array}$} \\
\hline & & & & & \multicolumn{3}{|c|}{ частота $v$, Гц } \\
\hline & & 1 & 3 & 5 & 1 & 3 & 5 \\
\hline $\begin{array}{l}\text { Тепло, отведенное в } \\
\text { кристаллизаторе, кДж }\end{array}$ & 3681 & 4490 & 4625 & 4706 & 4524 & 4895 & 5098 \\
\hline $\begin{array}{l}\text { Коэффициент } \\
\text { теплоотдачи, кДж/м² } \\
{ }^{\circ} \mathrm{C}\end{array}$ & 4601 & 7649 & 10125 & 11232 & 9906 & 14055 & 14745 \\
\hline $\begin{array}{l}\text { Толщина корки на } \\
\text { выходе из } \\
\text { кристаллизатора, мм }\end{array}$ & 13 & 11 & 10 & 10 & 10 & 9 & 8 \\
\hline $\begin{array}{l}\text { Средняя скорость } \\
\text { кристаллизации, } \\
\text { мм/мин. }\end{array}$ & 1,6 & 1,7 & 1,9 & 2,0 & 1,9 & 2,2 & 2,5 \\
\hline $\begin{array}{l}\text { Масса затвердевшего } \\
\text { сплава, кг }\end{array}$ & 0,22 & 0,25 & 0,45 & 0,64 & 0,41 & 0,88 & 1,05 \\
\hline $\begin{array}{l}\text { Глубина жидкой } \\
\text { лунки, м }\end{array}$ & 1,2 & 1,1 & 0,95 & 0,8 & 0,96 & 0,75 & 0,65 \\
\hline
\end{tabular}

Как показывают результаты таблиц 1 и 2, несмотря на более интенсивные теплообменные процессы в кристаллизаторе при газоимпульсном перемешивании, наиболее эффективным методом воздействия на параметры кристаллизации (скорость кристаллизации, масса затвердевшего сплава, глубина жидкой лунки) является вибрация.

Это объясняется тем, что воздействие газоимпульсного перемешивания на процессы формирования заготовки происходит, в основном только в пределах кристаллизатора, а воздействие вибрации через затвердевшую корку передается и на зону вторичного охлаждения, в которой происходит окончательное затвердевание заготовки. 
Полученные результаты и проведенные расчеты показывают, что вибрация и газоимпульсное перемешивание способствуют интенсификации теплообменных процессов в кристаллизаторе при формировании непрерывнолитой блюмовой заготовки.

Это обусловлено, в том числе и тем, что эти способы внешнего воздействия на затвердевающий металл усиливают гидродинамические процессы в кристаллизаторе и зоне вторичного охлаждения.

Усиление гидродинамических и теплообменных процессов в кристаллизаторе, вызванное внешними физическими воздействиями (вибрацией или газоимпульсным перемешиванием), оказывает влияние на формирование кристаллической структуры заготовок (рис. 1). Все структуры, как видно из этого рисунка, состоят из трех характерных зон: корковой зоны, зоны столбчатых и зоны равноосных кристаллов. Разница между структурами заключается в изменении ширин и дисперсности соответствующих $30 \mathrm{H}$.

В контрольной заготовке зона столбчатых кристаллов имеет максимальную ширину, а зона равноосных кристаллов занимает небольшую по ширине зону (рис. 1, a). Из-за того, что зона транскристаллизации является неравномерной, в некоторых местах по высоте заготовки образуются «мостики», под которыми формируются усадочные раковины и поры.

В результате обламывания ветвей дендритов при вибрационном воздействии ширина зоны столбчатых кристаллов сокращается в 2,5 раза, а фронт кристаллизации выравнивается по высоте.

При этом отсутствует возможность образования «мостиков», а ширина зоны равноосных кристаллов увеличивается (рис. 1, б). Обломки дендритов частично оседают на дно заготовки, уменьшая глубину жидкой лунки, а частично становятся дополнительными центрами кристаллизации затвердевающем расплаве (табл. 1). 
За счет силового воздействия упругой волны и кавитации разрушаются свободно растущие кристаллы в объеме расплава, при этом дисперсность зоны равноосных кристаллов заготовки повышается в разы, что уменьшает дендритную неоднородность по сечению. Об этом свидетельствует, практически, одинаковая плотность металла по сечению заготовок, формирующихся под воздействием вибрации $[2,3]$.

При газоимпульсном перемешивании металла происходит расширение зоны равноосных кристаллов, а ширина зоны столбчатых кристаллов уменьшается в 1,2 - 1,5 раза (рис. 1, в). Глубина жидкой лунки уменьшается за счет того, что увеличивается количество кристаллов, оседающих на дно заготовки (табл. 2). Уменьшению дендритной неоднородности заготовки по сечению способствует рост дисперсности свободнорастущих кристаллов в объеме расплава.

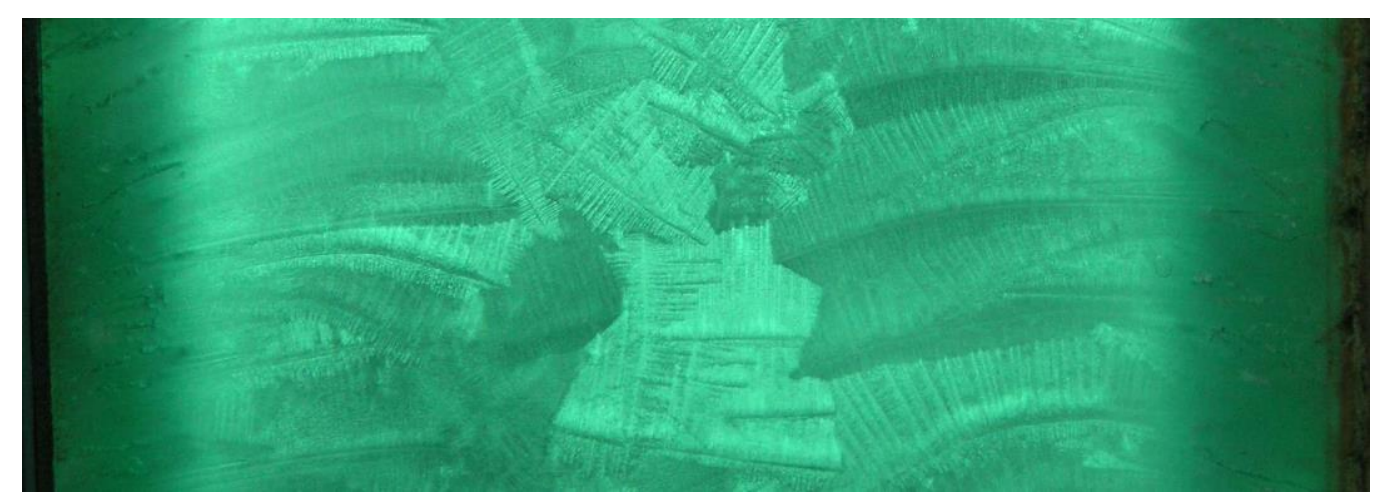

$a$

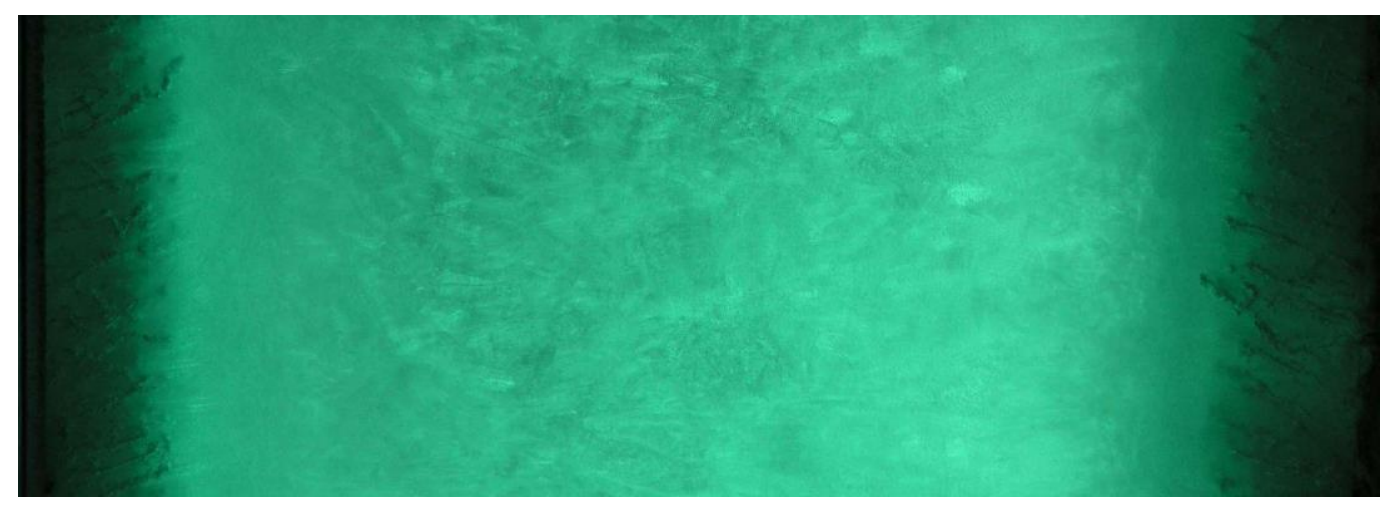


B

Рис.1. Макростуктуры непрерывнолитых блюмовых заготовок: $a$ - контрольный опыт; $\sigma$ - под действием вибрации; в - под действием

газоимпульсного перемешивания

Такие же результаты получены в работе [4] при затвердевании слябовой непрерывнолитой заготовки из стали 09Г2С, в которой заметно снижаются дефекты макроструктуры центральной зоны.

На основании анализа полученных результатов исследований установлено положительное влияние вибрации и газоимпульного перемешивания на гидродинамические, теплофизические условия формирования и первичную структуру блюмовой непрерывнолитой заготовки. Применение вибрации и газоимпульного перемешивания позволяет получать заготовки с мелкозернистой равномерно распределенной по всему сечению структурой, а также интенсифицировать тепло- массообменные процессы при ее формировании, что предопределяет перспективность промышленного использования этих методов физического воздействия на кристаллизующийся металл.

\section{Литература}

1. Сквориов А.А., Акименко А.Д. Теплопередача и затвердевание стали в установках непрерывной разливки. // М.: Металлургия, 1966. 190 с. 
2. Нурадинов А.С., Уздиева Н.С., Ахтаев С.С-С., и др. Формирование металлургических заготовок на установках полунепрерывного типа под воздействием вибрации // Труды КНИИ РАН. 2015. № 8. С. 102-114.

3. Нурадинов А.С., Эльдарханов А.С., Ахтаев С.С-С. Применение вибрации для повышения качества непрерывнолитой заготовки из низкоуглеродистой стали // Металлургия машиностроения. 2015. № 1. С. 32-35.

4. Нурадинов А.С., Эльдарханов А.С., Ахтаев С.С-С. Моделирование влияния газоимпульсных и вибрационных воздействий // Сталь. 2015. № 3. C. $42-45$. 